\title{
DUAS CIDADES DE JOAQUIM GUEDES: TEMAS URBANOS NOS PROJETOS DE BRASÍLIA - 1957 E CARAÍBA - 1976.
}

\section{Rogério Quintanilha, Mônica Junqueira de Camargo}

\section{Resumo}

Este artigo elabora uma comparação entre alguns temas urbanos tratados pelo arquiteto Joaquim Guedes em dois momentos distintos de sua carreira: a proposta apresentada ao concurso do plano piloto de Brasília, elaborada em 1957, e o projeto da cidade de Caraíba - BA, de 1976, núcleo destinado a abrigar os trabalhadores de uma mina de cobre. A partir de temas chave como natureza, duração da cidade, estrutura urbana e estratificação social, e baseado na própria fala do arquiteto ao apresentar seus projetos em duas teses acadêmicas, de doutorado e livre-docência, este paralelo observa como algumas posturas importantes aparecem em dois trabalhos tão distantes entre si no tempo e em suas condicionantes fundamentais.

\section{Palavras-chave}

Joaquim Guedes, Caraíba, Brasília, cidades novas

\begin{abstract}
This article presents a comparison among some urban themes treated by architect Joaquim Guedes at two different moments of his career: a proposal submitted to the contest's plan for Brasília, designed in 1957, and the design of the city Caraíba - BA, 1976, core designed to host the workers of a copper mine. From key themes such as nature, city lasting, urban structure and social stratification, and based on the architect's own speech to present their projects in two academic theses, Ph.D and Habilitation, this parallel reports how some important postures appear in both works widely separated in time and its fundamental determinants.
\end{abstract}

\section{Keywords}

Joaquim Guedes, Caraíba, Brasilia, new towns. 
Joaquim Manoel Guedes Sobrinho (1932-2008), arquiteto e urbanista, formado na FAU/USP em 1954, tem destacada atuação na área do urbanismo cuja qualidade e quantidade de trabalhos o coloca como referência para o estudo do urbanismo no Brasil. Recém formado trabalhou na SAGMACS - Sociedade de Análises Gráficas e Mecanográficas Aplicadas aos Complexos Sociais - com o padre dominicano francês Louis Joseph Lebret, um dos fundadores do Movimento Economia e Humanismo. A sua participação no plano para o desenvolvimento regional da bacia Paraná-Uruguai e no Plano Diretor de Ourinhos permitiu-lhe acompanhar a aplicação dos fundamentos introduzidos por Lebret, como o trabalho multidisciplinar, o uso da estatística e da probabilidade, a análise numérica e o estudo através da representação gráfica dos fenômenos que se dão no espaço e no tempo, que se constituíram a base instrumental da ação urbanística de Joaquim Guedes. Em 1957, Guedes participou com alguns colegas do concurso para Brasília.

Apesar dessa precoce aproximação ao urbanismo, Guedes só veio a se dedicar mais intensamente a essa área a partir da criação, em 1964, do SERFHAU - Serviço Federal de Habitação e Urbanismo do Banco Nacional da Habitação, tendo participado do Plano Urbanístico Básico para São Paulo (1968), do Plano de Ação Imediata para Porto Velho (1972) e as novas estruturas urbanas: Carajás, PA (1973), Marabá, PA (1973), Caraíba, BA (1976) e Barcarena, PA (1980).



FIGURA 1 - Proposta para plano piloto de Brasília - 1957. FONTE: TAVARES, 2004. 
Curiosamente, o primeiro e o último projeto apresentados nestes trabalhos são projetos para cidades novas. O primeiro é o projeto não executado, elaborado para a participação no concurso para o Plano Piloto de Brasília, em 1957. O último, tema da tese de livre-docência, é a cidade nova de Caraíba, no sertão baiano, núcleo urbano destinado a receber os trabalhadores de uma mina de cobre a ser instalada próxima ao distrito de Jaguarari, a aproximadamente $100 \mathrm{~km}$ da cidade de Juazeiro - BA.



FIGURA 2 - Proposta para o Plano Piloto de Brasília - 1957. Detalhe do centro da cidade.

Fonte: TAVARES, 2004.

Sua produção é ainda mais relevante na medida em que, como acadêmico, foi ao urbanismo que dedicou suas pesquisas em suas teses de doutorado Considerações sobre o desenvolvimento urbano, a propósito do plano de ação integrada de Porto Velho (1972) - e livre-docência - Um projeto e seus caminhos (1981), este sobre sua experiência no desenvolvimento do projeto para a cidade nova de Caraíba - BA, de 1976, o que revela a importância dada pelo próprio Guedes ao seu trabalho como urbanista. Além de constituírem relevante material de referência, URBANA, V.5, no 7, out.2013 - Dossiê: Urbanistas e Urbanismo: a escrita da história... - CIEC/UNICAMP 
estes dois trabalhos revelam o elevado interesse do arquiteto pelas questões urbanas, pelo seu pensamento e, notadamente, pelas questões metodológicas de projeto. Além disso, na tese de doutorado, Guedes revisa sua obra até o momento e remonta os caminhos de cada um, o que permite a investigação da transformação de seu pensamento sobre a cidade.

O próprio GUEDES (1981) elege conceitualmente os temas-chave de sua abordagem sobre Caraíba: natureza, duração da cidade, estrutura urbana, estratificação social e hierarquização internas, organização, situação institucional/administrativa do núcleo, conceitos de infra-estrutura, estratégias de custo, cultura e linguagem. Embora não sem alguma adaptação, é possível partir desses temas para tentar estabelecer algum paralelo possível entre esses dois projetos.

À primeira vista as semelhanças são poucas. O plano para Brasília é um projeto maior e mais ousado, uma cidade linear que pretendia se estruturar sobre uma divisão etária, restringindo os equipamentos infantis às Unidades de Vizinhança e as viagens dos adultos mais longa, pelos trilhos do metrô, enquanto Caraíba procura, ao contrário, olhar para a cultura e para a tradição arquitetônica de um lugar específico para tornar a cidade ao mesmo tempo nova e familiar ao habitante recém chegado. Nesse aspecto, o tempo que separa as duas propostas é relevante, pois o debate das ideias em meados dos anos 1950 difere daquele de 20 anos mais tarde. Enquanto para Brasília, as referências corbusianas constituíram a base, apesar do processo de revisão do urbanismo moderno já estar em pauta, com o polêmico e último CIAM em 1956; para Caraíba, as pré-existências de Nathan Rogers, a crítica tipológica de Aldo Rossi e a apropriação da cultura de massa de Robert Venturi já alimentavam as discussões internacionais. Acrescenta-se a esse quadro de referências, a cuidadosa leitura da cultura popular brasileira promovida pela arquiteta Lina Bo Bardi, com quem Guedes mantinha forte afinidade intelectual.

O sítio de implantação, a natureza, é também mais agressiva no caso da cidade baiana do que no planalto central e, por isso, lá há uma relação mais cuidadosa com os aspectos do meio, vegetação, tipo de solo e clima como determinantes de projeto. No entanto, é importante notar como a paisagem natural exerce força em um caso e outro: em Brasília, a cidade se desenvolve ao redor do lago, elemento natural préexistente que constitui para Guedes um elemento de restrição que, por sua vez, permite "soluções excepcionais". Essas possibilidades se referem, além das funções térmicas e de umidade, ao lazer e à vista, seja no núcleo original, seja na área de expansão na margem oposta, e por isso foram dispostos daquele modo. Dessa forma, URBANA, V.5, no 7, out.2013 - Dossiê: Urbanistas e Urbanismo: a escrita da história... - CIEC/UNICAMP 
Guedes dedica a primeira prancha de sua apresentação no concurso para o plano à apresentação de "todos os acidentes e característicos (sic) físico naturais do sítio, relevantes para nossos objetivos" (GUEDES, 1972, p. 48). Este tipo de visual também está presente em uma das primeiras de suas observações sobre o sítio escolhido para Caraíba:

Da área estudada verifica-se que as grandes visuais têm como perfil de fundo da paisagem dois sistemas de serras assim situados, para quem se encontrando em ponto de elevação média no Sítio Caraíba volta seus olhos para o Sul: à direita o complexo formado pela Serra da Conceição e Serra da Jacobina e à esquerda o conjunto da Serra da Itiuba.

Da planície avistamos o conjunto formado pelo represamento do Riacho Sulapa, primeiro no seu leito seco e depois surpreendente belo com o espelho d'água represada e as altas caraibeiras e braúnas às suas margens. É uma paisagem fortemente contrastante com a paisagem árida fornecida pela faixa de 2 a $3 \mathrm{~m}$ de altura, formada pela constante presença do "pau de rato", na caatinga-arbórea. (GUEDES, 1981, p. 30)

No entanto, o fator natural mais determinante para o desenho da cidade de Caraíba foi mesmo a insolação das casas. Para diminuir o calor, Guedes cria uma malha de ruas alongada no sentido leste-oeste, posicionando as residências em uma longa fachada contínua voltada a norte e a sul. Nas ruas transversais, evita a orientação ruim através de aberturas laterais e do estreitamento da via a fim de aumentar o sombreamento entre as construções. Finalmente, o material utilizado nas casas - o tijolo de solo cimento ao invés de concreto, madeira ou metal - foi escolhido por sua grande inércia térmica, opção também preocupada com a grande incidência de sol nas habitações.

Apesar das especificidades de cada caso, ambos compartilham uma preocupação comum à implantação de qualquer cidade nova: como se dará a cidade após estabelecido seu núcleo original, como se dará seu crescimento e como o projeto original restringirá ou não às ações futuras de uma cidade que tende a transformarse. Neste aspecto, Brasília e Caraíba encontram-se em situações também muito distintas. Enquanto a preocupação sobre a nova capital era a de guiar um crescimento que parecia inevitável, a preocupação em Caraíba era propiciar a sobrevivência do núcleo após a possível extinção da mina, prevista para acontecer em 15 anos após sua inauguração. Em ambos os casos, Guedes liga este processo à situação institucional/administrativa do núcleo, uma sede do governo federal e outra propriedade de uma mineradora estatal. A opção em ambas é por uma cidade aberta que possa tornar-se independente de suas funções iniciais. 


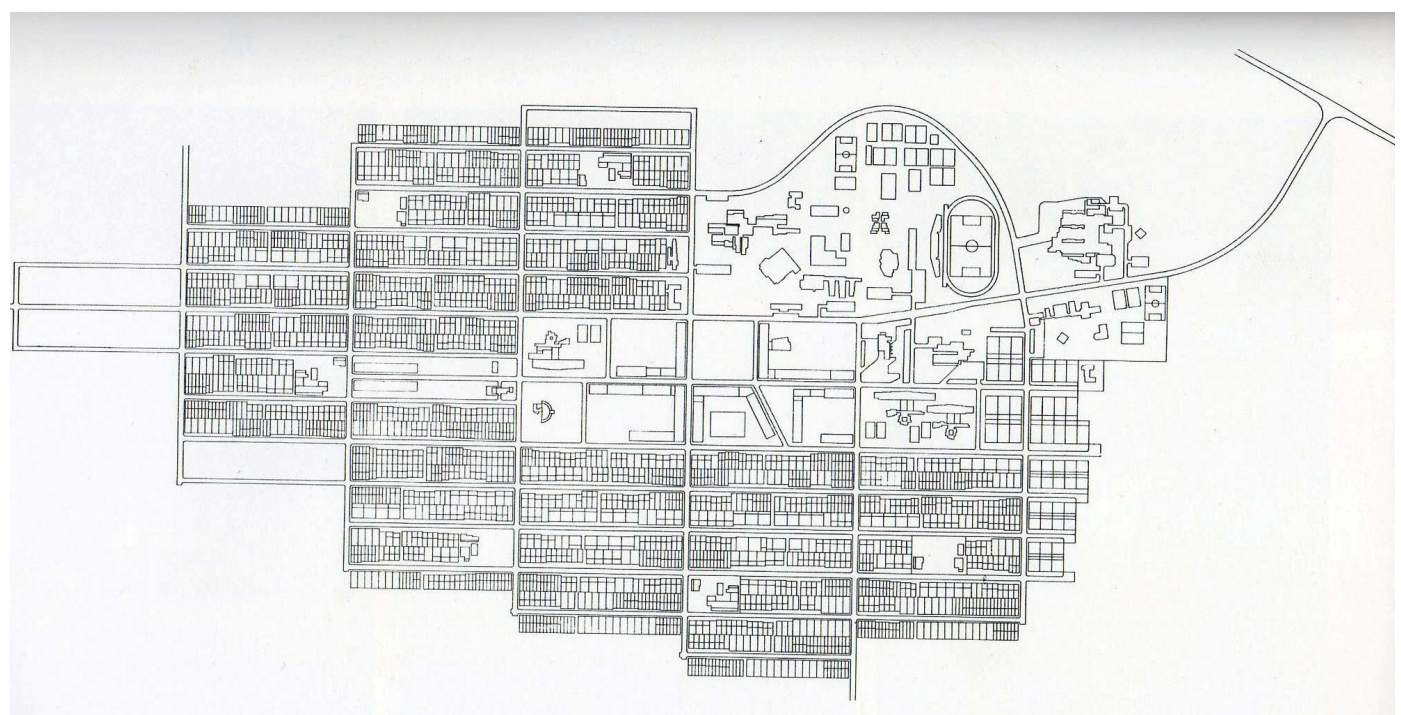

FIGURA 3 - Projeto da cidade nova de Caraíba - 1976. Fonte: CAMARGO, 2000.

A discussão sobre o tema cidade aberta versus cidade fechada é uma das mais debatidas por Guedes. Em Caraíba, define "cidade fechada" como um núcleo totalmente em poder e sob responsabilidade da empresa, rígido e planificado, em que os usuários são passivos. No entanto, este modelo estritamente ligado à empresa não revela grandes possibilidades de que a cidade sobreviva à exaustão da mina, na época previsto para 15 ou 20 anos. Guedes, então, procura alternativas para viabilizar essa sobrevivência: a agricultura, embora necessite de grandes investimentos devido aos tipos de solo e clima adversos, pode encontrar um caminho de sobrevivência nos produtos regionais. Sugere, inclusive, a implantação de um plano piloto de colonização próximo ao centro urbano que aproveite o excedente do sistema de adução de água para o núcleo.

Nota-se que, ao confrontar as possibilidades e os custos da agricultura, Guedes conclama a tecnologia futura para resolver a questão lembrando que, considerando um esgotamento da mina em 15 anos, há uma distância de 10 anos a partir da implantação do projeto para planejar e incorporar tecnologia capaz de permitir essa produção.

Embora configure uma situação oposta, controlar o crescimento em vez de evitar o decréscimo, Guedes também espera que a tecnologia futura possa ajudar a resolver um dos problemas de sua proposta para Brasília: a travessia do lago. Propondo núcleos que cresçam ao seu redor, Guedes entende que a travessia eficiente entre esses pólos de crescimento e o núcleo original é fundamental para que a cidade cresça de forma coesa. 


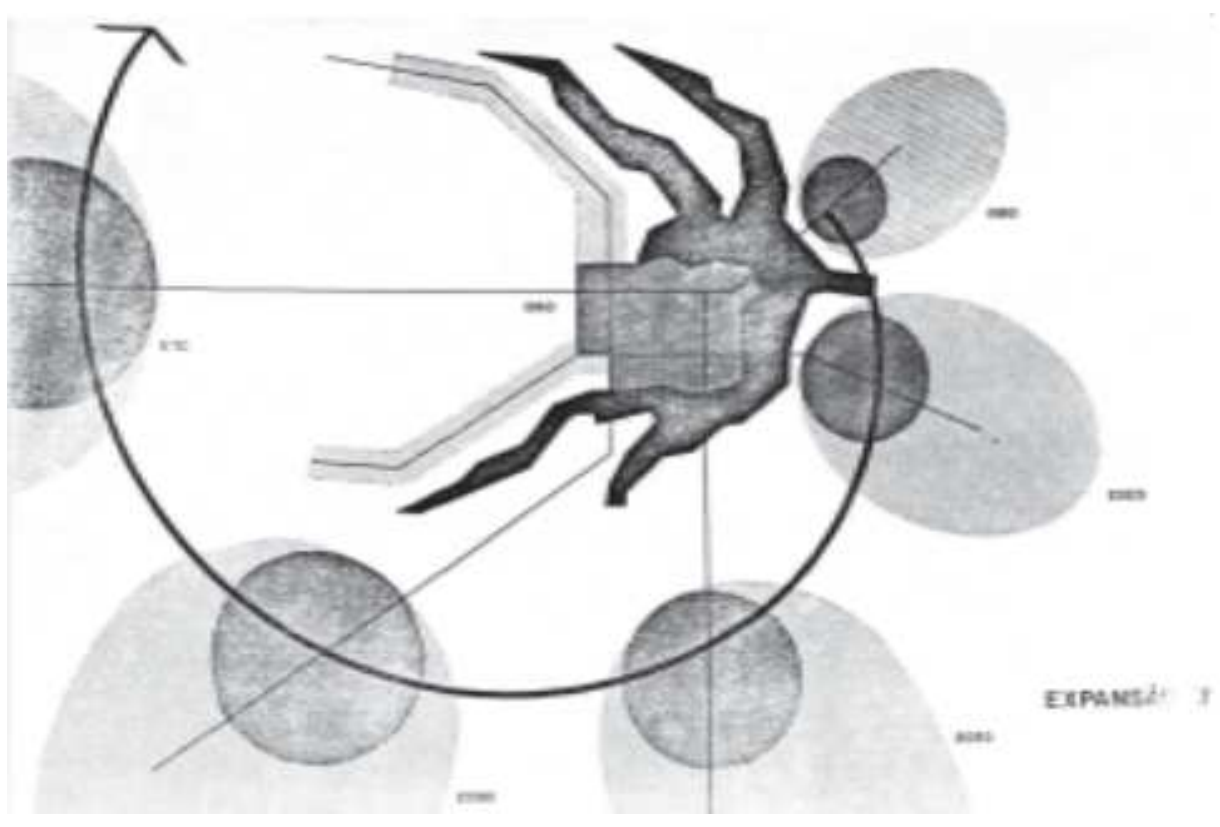

FIGURA 4 - Proposta de crescimento para Brasília. Fonte: TAVARES, 2004.

Ao comentar esse crescimento, Guedes tem para Brasília e mesma posição adotada para Caraíba: a cidade deve desvincular-se da sua estrita função inicial administrativa e tornar-se uma cidade múltipla, dinâmica e de livre crescimento. Esta posição contrariava princípios e limitações do edital (a Brasília de Guedes estava prevista para iniciais 1.200.000 hab.) e causou a eliminação do projeto de Guedes que, segundo depoimento do arquiteto (PÓS n.8, 2000), era o único a trabalhar com esse crescimento sem a necessidade de cidades-satélite. Não de forma concêntrica mas em núcleos, a proposta de modelo de expansão contínua do projeto apóia-se, assim, na capacidade tecnológica e de transporte de relacioná-los com o núcleo central que permanece "uno, incongestionável, indivisível e proporcional" (GUEDES, 1972 , p. 62) mas que com eles constitui uma cidade total.

Na realidade, a preocupação com o transporte é marca decisiva no desenho das duas cidades. A Brasília linear apóia-se decisivamente sobre a linha de metrô subterrâneo na área central e semi-enterrado nas demais, com estações a cada kilômetro. Assim, o cidadão atingiria qualquer ponto do centro da cidade rapidamente através de um único meio de transporte. Esse eixo também seria a guia da rede de distribuição de água, esgotos e outros serviços.

O transporte rápido também seria eficiente na resolução do problema da estratificação social. Ao contrário de propostas como a de Lúcio Costa, por exemplo, a Brasília de Guedes aborda o fenômeno como realidade e busca saídas arquitetônicas, URBANA, V.5, no 7, out.2013 - Dossiê: Urbanistas e Urbanismo: a escrita da história... - CIEC/UNICAMP 
não para ignorar ou para superar este tipo de segregação, mas atenuá-los. Neste caso, permitir o acesso dos bairros proletários aos equipamentos normalmente disponíveis apenas nos bairros abastados é a forma encontrada pelo urbanismo para amenizar suas diferenças. Nota-se que Guedes coloca, assim, o transporte público e de massa o mais possível a favor da cidade e da maioria da população, reservando o transporte individual ao lado oposto do lago onde estão localizadas as casas de exceção.

O mesmo eixo possui ainda a função de controlar os custos urbanos, a densidade e evitar que a área livre disponível se sobrecarregue com a função de transporte. O eixo de transporte público é tão importante que Guedes chama a atenção para a urgência de sua solução:

Observaríamos que o nosso esquema favorece (...) o sistema de transporte coletivo que é realmente o único capaz de resolver o problema das grandes cidades. Se fôssemos resolvê-lo na escala individual ou do automóvel, para uma determinada área construída de trabalho, precisaríamos num futuro não próximo de uma outra, três ou cinco vezes maior, para estacionamento. 0 automóvel é um veículo de passeio. Isto, sem contar a demanda muito maior de comprimento de vias para circulação, o que acarretaria uma diminuição de densidade bruta global e custos sociais elevados. (GUEDES, 1972, p. 60).

A distinção entre as opções de acessibilidade e do sistema de transporte nas respectivas cidades, decorre do caráter e da escala de cada uma e também do tempo que as separa. A mudança da capital coincide com o grande incentivo à indústria automobilística que privilegiou o transporte rodoviário e individual, ainda assim para Brasília, Guedes optou por estruturá-la a partir do transporte de massa que, segundo ele, teria sido um dos argumentos para a desclassificação de sua proposta. Em Caraíba as distâncias foram definidas para o deslocamento a pé. Neste caso, Guedes estabelece um diagrama a partir da área de abrangência dos equipamentos: berçário, escolas, biblioteca, igreja, mercado, cinema e centro de saúde, por exemplo, devem ser acessados a pé. Há vias exclusivas para pedestres que cortam as quadras para encurtar as distâncias e facilitar os deslocamento. Já o hospital foi localizado na entrada da cidade mais próxima à mina, visando atender aos trabalhadores.

O acesso fácil ao berçário faz parte também do plano para Brasília. Para a capital, Joaquim Guedes estabelece uma escala de equipamentos conforme a idade de seu público, e aqueles dedicados às crianças estão dentro das unidades de vizinhança, dispensando grandes viagens. Em Caraíba, o critério é diferente, baseado nas relações humanas propiciadas por cada equipamento. No caso de Caraíba, essas relações estão 
no centro da preocupação de Guedes ao pensar a cidade pois as diferenças sociais, aqui especialmente ligadas ao cargo, função e salário dentro da empresa, são significativas.

Para GUEDES (1972, p.235), "projetar uma cidade mineira sem classes é ilusório, ingênuo e anti-histórico em nossa realidade" trabalhando essa questão delicada de maneira igualmente cuidadosa. Buscou evitar a solução tradicional das cidades de companhia, dividindo a população em três bairros de trabalhadores braçais, médios e superiores, e minimizar a segregação diluindo as fronteiras de modo a ter funcionários de classes diferentes em um mesmo quarteirão, ainda que identificados pelo padrão e tamanho da construção. Da mesma forma, foram deixados alguns vazios nas quadras a serem ocupados por moradores que não pertenciam à companhia, vislumbrando uma passagem mais amena à condição de cidade aberta. Guedes esperava que a proximidade, a convivência, a liderança cultural e a preocupação social das classes mais altas pudessem criar um sistema de relações pessoais harmônico. A cidade foi concebida então como o palco desses encontros,e neste aspecto a praça surge como o elemento da coesão social: entendidas como o coração da cidade, são o palco destes encontros e atividades. Essas praças, na verdade um sistema de praças, que incorpora cada qual uma escola infantil e comércio local, dominam a planta de Caraíba tanto quanto o eixo de transporte domina a estrutura linear do plano para Brasília. Em cada caso, o desenho corresponde e revela uma lógica baseada no funcionamento de seus equipamentos urbanos. 


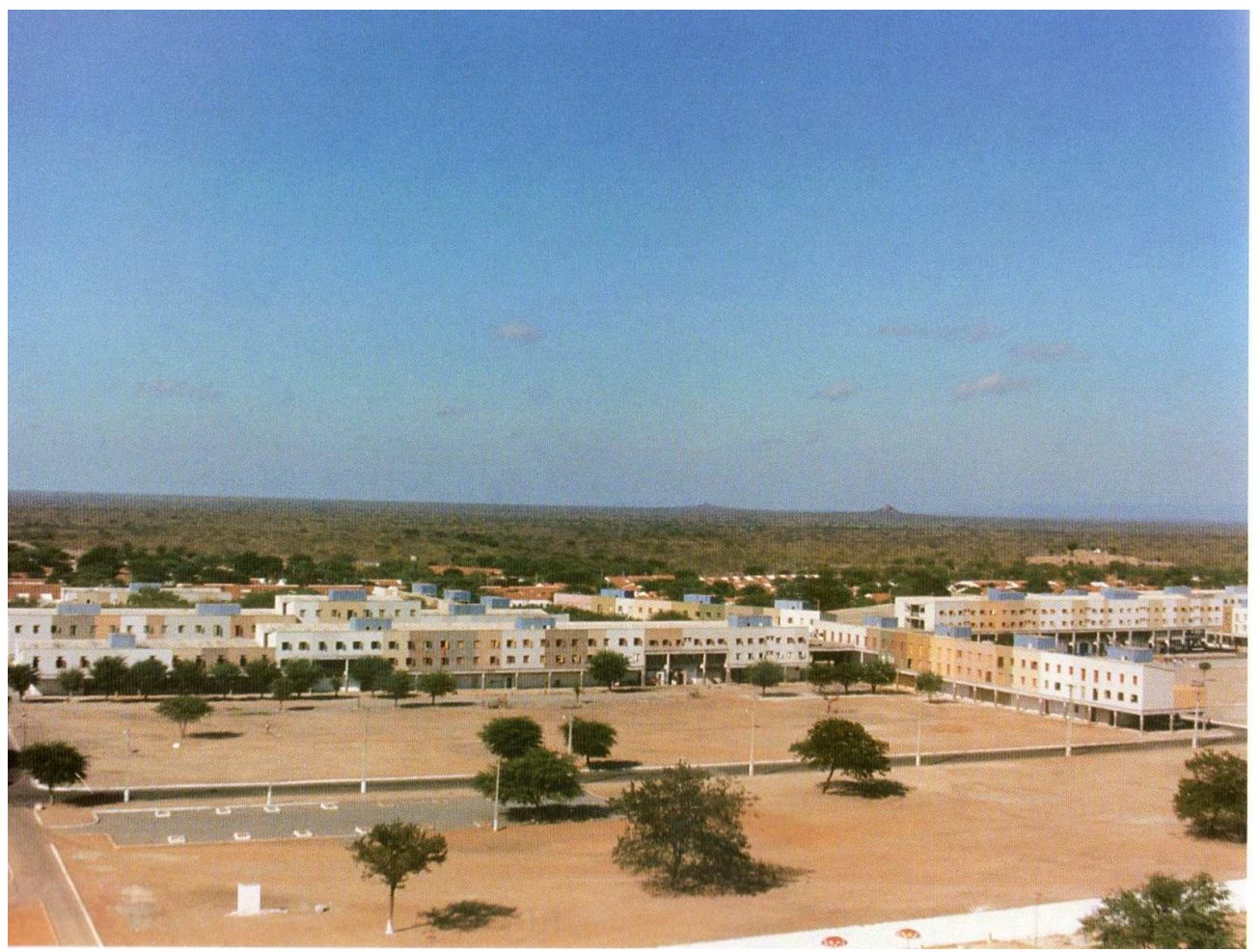

FIGURA 5 - Vista aérea de uma das praças de Caraíba. Fonte: CAMARGO, 2000.

A praça principal de Caraíba, de maior dimensão e destaque, cumpre o papel de core, à qual se integram escolas infantis e secundárias, os equipamentos culturais e esportivos, sendo blocos que a conformam de três andares e de multiuso. $O$ térreo com comércio e serviços, os andares superiores com habitação.

Embora esta comparação seja apenas uma análise pontual sobre cada projeto, é possível observar como, diante de situações tão díspares, Guedes mantém determinadas posturas fundamentais: a incorporação da paisagem, o conforto ambiental, o desenho urbano marcado pelos equipamentos, as questões de segregação e, principalmente, a defesa da cidade como um organismo vivo, multifuncional e dinâmico.

\section{Bibliografia}

CAMARGO, Mônica Junqueira de. Joaquim Guedes. São Paulo: Cosac \& Naif, 2000. GUEDES, Joaquim. Considerações sobre planejamento urbano, a propósito do Plano de Ação Imediata de Porto Velho. Tese de Doutoramento - Faculdade de Arquitetura da Universidade de São Paulo, 1972.

GUEDES, Joaquim. Um projeto e seus caminhos. Tese de Livre Docência Faculdade de Arquitetura da Universidade de São Paulo, 1981. 
PÓS. Revista do Programa de Pós-Graduação em Arquitetura e Urbanismo da FAU-USP/Universidade de São Paulo. Faculdade de Arquitetura e Urbanismo. Comissão de Pós-Graduação - v.1 (1990). São Paulo: FAU, 1990. n.8 dez. 2000.

TAVARES, Jeferson C. Projetos para Brasília e a cultura urbanística nacional. Dissertação de Mestrado - Escola de Engenharia de São Carlos da Universidade de São Paulo, 2004. 